\title{
Influenza vaccine effectiveness, 2010/11
}

A Steens ${ }^{1}$, W van der Hoek (Wim.van.der.Hoek@rivm.nl) ${ }^{1}$, F Dijkstra ${ }^{1}$, M van der Sande $^{1}$

1. Epidemiology and Surveillance Unit, Centre for Infectious Disease Control, National institute for Public Health and the Environment, Bilthoven, the Netherlands

Citation style for this article:

Steens A, van der Hoek W, Dijkstra F, van der Sande M. Influenza vaccine effectiveness, 2010/11. Euro Surveill. 2011;16(15):pii=19843. Available online: http://www. eurosurveillance.org/ViewArticle.aspx?Articleld=19843

Article published on 14 April 2011

To the editor: The editorial [1] and the articles related to it published on 17 March 2011 in Eurosurveillance provide important information on preliminary midseason influenza vaccine effectiveness (VE) estimates for the 2010/11 season. Reliable VE estimates are essential for effective communication and planning of scarce resources. It is important to assess concordance between pooled European data [2] and national estimates, to evaluate on the one hand whether pooling indeed provides more robust estimates, and on the other hand, to explore potential geographical variation in such estimates.

In the Netherlands, we have been estimating effectiveness of the influenza vaccine in preventing medically attended laboratory-confirmed influenza-like illness (ILI) using the test-negative case-control approach for several years. While incorporating this in the routine $\mathrm{ILI} /$ influenza surveillance in primary care limits the possibility to optimise the design, to avoid bias, and to adjust for potential confounding, it ensures sustainability and assessment of annual variation. Unfortunately, our limited sample sizes do not allow strain-specific estimates, result in large confidence intervals, and make adjustment for age and underlying conditions challenging. Therefore, to increase power and obtain more valid VE estimates, we very much support pooled European analysis [2].

We estimated the VE using logistic regression on all medically attended ILI patients in the sentinel surveillance system with disease onset between the week in which influenza virus was encountered for the first time in the season and the end of April, the following year. For the current season, we included cases up to 21 March 2011. For 2009/10 and 2010/11, we excluded cases if the period between disease onset and date of swabbing was greater than seven days.

The crude effectiveness of the trivalent seasonal influenza vaccine in 2006/07, 2007/08 [3], 2008/09 [4], and of the monovalent 2009 influenza $A\left(\mathrm{H}_{1} \mathrm{~N}_{1}\right)$ pandemic vaccine in $2009 / 10$ ranged from $20 \%$ to $60 \%$. Adjustment for age lowered the VE estimates and widened the confidence intervals (Table).

The crude VE estimate for the 2010/11 vaccine was $46 \%$ (95\% confidence interval: $9-67$ ), which is similar to what has been reported in other European studies [2]. The 2010/11 VE estimate was lower when only individuals with an indication for vaccination (underlying condition or aged 60 years or older) were included.

It is worrying that patterns similar to those observed in the Netherlands are observed on a European scale. In particular, the consistent pattern of reduced VE estimates following correction for potential confounding by age or underlying conditions warrant further studies to develop methodologies for robust, non-biased VE estimates.

\section{TABLE}

Influenza vaccine effectiveness estimates per season, the Netherlands, 2006/07 - 2010/11

\begin{tabular}{|l|l|l|l|l|}
\hline Influenza season & Vaccinated / total positive & Vaccinated / total negative & \multicolumn{1}{c|}{$\begin{array}{c}\text { Crude VE (95\% Cl) } \\
\text { Age-adjusted VE (95\% Cl) }\end{array}$} \\
\hline $2006 / 07$ & $9 / 72$ & $25 / 144$ & $32 \%(-55$ to 70$)$ & $6 \%(-132$ to 62) \\
\hline $2007 / 08$ & $10 / 141$ & $38 / 236$ & $60 \%(17$ to 81$)$ & $59 \%(7$ to 82$)$ \\
\hline $2008 / 09$ & $20 / 167$ & $45 / 311$ & $20 \%(-41$ to 54$)$ & $19 \%(-56$ to 58$)$ \\
\hline $2009 / 10^{a}$ & $6 / 36$ & $72 / 258$ & $48 \%(-29$ to 79$)$ & $35 \%(-76$ to 76$)$ \\
\hline $2010 / 11$ & $26 / 217$ & $52 / 260$ & $46 \%(9$ to 67$)$ & $5 \%(-80$ to 49$)$ \\
\hline
\end{tabular}

$\mathrm{Cl}$ : confidence interval; VE: vaccine effectiveness.

${ }^{a}$ Vaccine effectiveness calculated for the adjuvanted MF-59TM 2009 influenza A(H1N1) pandemic vaccine. 


\section{References}

1. Puig-Barberà J. 2010-2011 influenza seasonal vaccine, preliminary mid-season effectiveness estimates: reason for concern, confounding or are we following the right track?. Euro Surveill. 2011;16(11):pii=19821. Available from: http://www. eurosurveillance.org/ViewArticle.aspx?Articleld=19821

2. Kissling E, Valenciano M, I-MOVE case-control studies team. Early estimates of seasonal influenza vaccine effectiveness in Europe, 2010/11: I-MOVE, a multicentre case-control study. Euro Surveill. 2011;16(11):pii=19818. Available from: http:// www.eurosurveillance.org/ViewArticle.aspx?Articleld=19818

3. Dijkstra F, van Gageldonk-Lafeber AB, Brandsema P, Friesema IHM, Robert-Du Ry van Beest Holle M, van der Lubben IM, et al. Jaarrapportage respiratoire infectieziekten 2007/2008. [Annual report on respiratory infectious diseases 2007/2008]. Bilthoven: Rijksinstituut voor Volksgezondheid en Milieu. 2008. Dutch. Available from: http://www.rivm.nl/bibliotheek/ rapporten/210231003.pdf

4. Dijkstra F, van 't Klooster TM, Brandsema P, van GageldonkLafeber AB, Meijer A, van der Hoek W. Jaarrapportage surveillance respiratoire infectieziekten 2009. [Annual report on surveillance of respiratory infectious diseases 2009]. Bilthoven: Rijksinstituut voor Volksgezondheid en Milieu. 2010. Dutch. Available from: http://www.rivm.nl/bibliotheek/ rapporten/210231006.pdf 